\title{
2. Obstacles to Building Effective Theory about Attitudes and Behaviours Towards Technology
}

\author{
Mary Tate \\ Victoria University of Wellington \\ Joerg Evermann \\ Memorial University of Newfoundland
}

\begin{abstract}
Some widespread approaches and practices in information systems research might be doing more harm than good, and potentially acting as obstacles to effective theory building. Theories of attitudes and behaviours towards technology have formed part of the core of the information systems discipline for 30 years, but, despite this, there is still relatively little consensus about the definition, operationalisation and nomological net of many key constructs. There are also ongoing calls for theory that is more salient to practice. In this conceptual chapter, we identify 10 potential obstacles to effective theory building that could occur during presentation of previous literature, theory development and research design. We define each potential obstacle, explain why it is a problem and offer some alternatives.
\end{abstract}

\section{Introduction}

Ever since the days of Keen and Weber, influential thinkers within the information systems (IS) discipline have bemoaned the lack of a cumulative research tradition (Keen, 1980; Weber, 1997). For the discipline to progress, it has been suggested, IS research needs fewer frameworks and more ongoing cumulative lines of inquiry (Keen, 1980; Weber, 1997).

More recently, some have argued that the academic legitimacy of the field does not necessarily depend on having a core of theory, but on the strength of results and their salience to practice (Lyytinen and King, 2004). Despite this, there continues to be a strong emphasis, especially in our top journals, on the 
importance of the theoretical contribution of research: 'The contribution of the paper is its theory (backed by the evidence), not the empirical evidence itself (however interesting that may be)' (Seddon, 2006, p. 5).

A core component of the body of IS theory is theories of attitudes and behaviours towards technology, such as the technology acceptance model (TAM) (Davis et al., 1989), the task-technology fit model (Goodhue and Thompson, 1995) and the service quality of the IS function (Pitt et al., 1995). Despite 30 years of research, some theories of attitudes and perceptions towards technology are characterised by inconsistent, even conflicting, definitions and operationalisations, while others - considered more stable-have made a limited contribution to knowledge. As an example of the first, the definition of online service quality in different contexts has included 'overall affect towards a web portal' (Yang et al., 2005), 'intent to repurchase' (Sum et al., 2002) and 'interactions between citizens and government officials' (Teo et al., 2009). As an example of the second, the core constructs of the TAM (perceived usefulness and perceived ease of use) have been reasonably consistent but the overall theoretical contribution of the accumulated body of TAM research has been criticised on a number of counts (Benbasat and Barki, 2007). These include: a bewildering number of extensions with marginal incremental value; little overall insight for our practitioner community into the design factors that lead to usefulness and ease of use; and the possibility that the dominance of TAM has constrained the inclusion of other relevant beliefs in our theories (Benbasat and Barki, 2007).

Given this situation, it is possible that some aspects of the way we commonly conduct theory development and research design would benefit from critical evaluation. In this chapter, we present a set of potential obstacles to effective theory building in this area of information systems. We have concentrated on quantitative methods, as these are the most widely used in studies of attitudes and behaviours towards technology in top-ranked journals. While each issue has an extensive literature in its own right, our intention is to provide a broad view of the potential impact of these issues on IS theory building, rather than an in-depth discussion of each issue. A further aim of this chapter is to introduce literature from reference disciplines, which offers a more in-depth discussion of these issues.

Some of our assertions run counter to what might be termed received wisdom in our field, and contrary views are possible and indeed welcome. Overall, we wish to stimulate debate about these important issues in the hope that this discourse will contribute to an overall improvement in the quality of theory building in the discipline. We have divided the issues into three sections: those associated with presenting previous literature, those associated with theory building and those associated with research design. We briefly define each issue and explain why it is a problem for effective theory building, and offer some examples and alternatives. 


\section{Obstacles in Presenting Previous Knowledge}

Literature reviews have 'played a decisive role in scholarship' because 'science is a cumulative endeavour' (vom Brocke et al., 2009, p. 1). The literature review is the artefact that enables the researcher to identify the gap in knowledge that their research will address and to distinguish the original contribution of the research from what has gone before. The literature review underpins the development of new theory. This means that issues with the presentation of previous literature can act as constraints on theory building.

Before identifying potential problems, we first examine different types of literature reviews. Figure 2.1 shows four methods of literature review: narrative review, descriptive review, vote counting and meta-analysis. These four review methods are placed in a qualitative-quantitative continuum to illustrate their different foci (King and He, 2005). The 'narrative review' is the traditional way of reviewing research literature. It is conducted by verbally describing past studies, and focusing on theories and frameworks, elementary factors and their research outcomes, with regard to arriving at hypothesised relationships (King and He, 2005) (Figure 2.1).

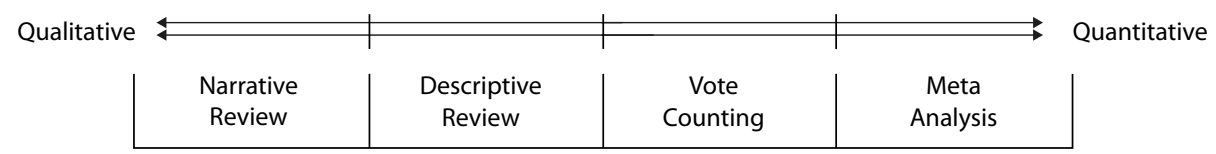

\section{Figure 2.1 Literature Review Methods on a Qualitative-Quantitative Continuum}

A descriptive review focuses on revealing an interpretable pattern from the existing literature (Guzzo et al., 1987). It produces some quantification-often in the form of frequency analysis, such as publication time, research methodology, research outcomes, and so on. Such a review method often has a systematic procedure including searching, filtering and classifying processes. The reviewer treats an individual study as one data record and identifies trends and patterns among the papers surveyed (King and He, 2005). The outcome of such a review is often claimed to be representative of the state of the art of a research domain.

Vote counting is generally used to draw inferences upon focal relationships by combining individual research findings (King and He, 2005). Here a tally is made of the frequency with which existing research findings support a particular proposition. Most likely it is applied to generate insights from a series of experiments. The premise underlying this approach is that repeated results in the same direction across multiple studies - even if some of them are nonsignificant - might be more powerful evidence than a single significant result (King and He, 2005). We were not able to identify any examples of this type of literature review in the IS area. 
Meta-analysis aims at statistically providing supports to a research topic by synthesising and analysing the quantitative results of many empirical studies (King and He, 2005). In most cases, it might specifically examine the relationships between certain independent variables (IVs) and dependent variables (DVs) derived from existing research findings. Qualitative studies have to be excluded from a meta-analysis due to its extremely quantitative nature. Only studies with comparable effect size metrics can be included in a meta-analysis.

Of these types, the narrative literature review, which aims to synthesise previous knowledge, is the most commonly used form in IS research papers. In this section, we examine some obstacles that can arise from the approach and stance adopted by the researcher to presenting previous research.

\section{The Unconsciously Subjective Literature Review}

\section{Description}

Literature reviews are almost always a form of qualitative research. A narrative literature review in particular is a qualitative and subjective review that, far from being value neutral, requires and invites the researcher to adopt a distinct viewpoint. The subjective influences stem from a consideration of what literature sources (journals, conferences, range of publication dates) are of sufficient importance to consider, which theories provide sufficient evidence to be trusted and which methods are considered sufficiently rigorous to yield valid results (vom Brocke et al., 2009). There are few reviews that make explicit all assumptions underlying the scope and selection of studies or that employ multiple researchers to alleviate individual biases. This means that the researcher adopts a value-neutral stance while making unconscious (or unacknowledged) subjective judgments.

Narrative literature reviews are subjective in the identification of concepts and relationships, the establishment of their equivalences across studies and the assessment of validity. All researchers have subjective positions on these and related questions, of which they might not even be explicitly aware. The narrative literature review thus necessarily represents a qualitative and subjective interpretation of the literature. It is therefore not unusual for 'two reviews to arrive at rather different conclusions from the same general body of literature' (Guzzo et al., 1987, p. 408).

Rigorous criteria for selection and evaluation of literature are mostly reserved for review articles, while the literature review for 'regular' articles does not usually exhibit these characteristics. Descriptive literature reviews might 
be only slightly less subjective, but the subjective criteria are more explicit. Descriptive literature reviews require the researcher to articulate a systematic procedure for searching, filtering and classifying research articles.

\section{Why is This A Problem, and What Should We Do Instead?}

In the IS field, a number of constructs of interest - such as service quality, diffusion of innovation and technology adoption - have been characterised by a complex and heterogeneous literature. It is possible to find reputable, previously published studies backed by empirical studies that show that A causes B, and equally reputable studies, also backed by empirical evidence, that find just the opposite. A literature review that uncritically accepts both positions without being able to explain the difference in findings is worse than useless. It signals to the reader and future researchers that there is no problem in this area of research-that somehow the theories might be commensurable, usually by ensuring that the concepts are sufficiently wide or elastic that contradictory results are possible.

Moving to a descriptive review or a meta-analytic study will assist this issue. A descriptive review needs to articulate the criteria adopted for the selection and interpretation of the studies. Hence, being sufficiently explicit about the relevant literature sources, and being explicit not only in what to include but also in what to exclude, and why, will allow researchers to come to a consensus on the state of the art in some research area.

For a meta-analytic review, these criteria must include not only the desirable properties of theories (the ability to explain and predict, parsimony and coherence with other theories), but must also extend to the method employed by prior studies. Rarely are the results and research methods of prior work critically examined based on current standards of validity. There is no point including flawed studies in a meta-analysis. Frequently, the details of previous studies are assumed to be correct. After all, the paper has been published, perhaps in a 'good' journal; however, criteria for validity are not fixed over time and what was acceptable 20 years ago might not be acceptable anymore. For example, exploratory factor analysis (EFA) is not as acceptable as it was 20 years ago, before the widespread availability of structural equation modelling, and many now warn against reliance on exploratory techniques for various reasons. Hence, it behoves researchers to reassess EFA-based results, rather than reusing them indiscriminately. An extended debate on this topic can be found in a special issue of Multivariate Behavioral Research (volume 31, issue 4) (David, 1996; McDonald 1996; Maraun, 1996a, 1996b, 1996c; Mulaik, 1996; Rozeboom, 1996; Schonemann, 1996a, 1996b; Steiger, 1996a, 1996b). 
In summary, since the literature review is inherently subjective and cannot be value neutral, it is important that this process is as transparent as possible, and is based on explicitly acknowledged criteria for the selection and evaluation of articles. This includes a critical examination of the method applied according to current standards and heuristics in research methodology.

\section{Meaning Variance: Does a rose by any other name smell as sweet?}

\section{Description}

Sometimes, the same term is used for constructs that are measured with different, non-equivalent items, while different terms are used for constructs that include some of the same items (Barki, 2008). These ambiguous constructs are then included in different theory nets. This tends to create and compound problems with meaning variance. Meaning variance occurs when the same term is used but it is defined or operationalised differently, so the constructs being synthesised or compared are not equivalent. This has problems for theory building as researchers can 'utter the same words, but the words have different meanings, so any logical comparison of their utterances is precluded, leaving adherents of rival theories simply talking past one another' (Curd and Cover, 1998, p. 222).

By way of example, a paper by Petter et al. (2008) provides a narrative literature review where the equivalence of different constructs is argued by the authors, and could be open to other interpretations. They argue that constructs identified as instances of 'service quality' incorporate other quite disparate constructs, including '[t]he effective role of the technical staff (service quality)'; 'the retention of service staff (and the related funding)' and the 'competency of support staff, vendor support, and availability of training' (Petter et al, 2008, p. 245).

Many arguments and counterarguments have been proposed concerning the definition and operationalisation of service quality, particularly the ServQual instrument, variations of which are used for measuring customer perceptions of service quality in a range of contexts. According to the Google Scholar search engine, ServQual (Parasuraman et al., 1988) has been cited more than 6000 times.

Despite the popularity of ServQual, many reputable studies have failed to replicate the five dimensions of service quality posited by the original authors (Babakus and Boller, 1992; Carman, 1990; Parasuraman et al., 1991). Although this issue is not fully resolved, it is frequently glossed over. ServQual is frequently perceived as 'the cornerstone on which all other works [about service quality] have been built' (Sureshchandar et al., 2002, p. 10). 


\section{Why Is This A Problem, and What Should We Do Instead?}

The narrative literature review, as a qualitative, interpretative and subjective activity, allows the researcher much freedom in interpreting the input texts as well as in the production of the output text (the review). Thus, when the review does not provide a detailed examination of different concepts and their relationships, but instead glosses over any differences or particularities of their definition and operationalisations, the result is likely a conceptual mash-up that is overly broad in scope and includes related, but clearly distinguishable concepts. Moreover, the boundaries of the concept might become unclear or 'fuzzy'. When such fuzzy concepts are used within a nomological network of a theory, they might lead to tautologies, the inability to generate precise hypotheses or the inability to generate hypotheses that are unique to that theory. Moreover, these fuzzy concepts are then promoted to future researchers as state of the art, thus perpetuating the mistakes of the original review and endangering subsequent research.

As an alternative, a more nuanced treatment of discourse, which aims to identify the important areas of difference, rather than the points of similarity, is provided by Sylvester and Tate (Sylvester and Tate, 2008; Sylvester et al., 2007). These authors offer a representation of the richness of the service quality discourse, using soft-systems analysis and rich pictures (Sylvester et al., 2007). In addition, a critical discussion of the social and environmental factors associated with the discourse provides further insights, such as the importance of the determined ongoing advocacy of the original ServQual authors in developing and perpetuating the ServQual stream of research (Sylvester et al., 2007).

Overall, there are a number of research areas within information systems that are contradictory and heterogeneous, and thus not truly cumulative. Attempting to synthesise them glosses over important areas of difference and this tends to have the effect that the same term is used relatively indiscriminately to encompass an increasingly broad and vague set of definitions and operationalisations. A critical analysis or a more nuanced discussion that focuses on the diversity of opinions (Cooper, 1988; Killduff and Mehra, 1997; Rosenau, 1992) might be more appropriate in these circumstances.

\section{Using Literature as Lego Blocks}

\section{Description}

Coverage of previous literature is usually assumed to mean some kind of synthesis. Novice researchers are exhorted to integrate (synthesise) previous literature rather than simply summarise one study after another. Thus, recommendations of conceptcentric rather than study-centric reviews abound (Webster and Watson, 2002). Furthermore, literature reviews exhort the researcher to find gaps in the theories 
they examine in order to motivate future research. This is further exacerbated by the insistence of reviewers and editors that a theory to be tested (and published) must be based on the literature. To the inexperienced and novice researcher, this means that 'combining the boxes' appears a safer method than introducing new and original thought.

\section{Why Is This A Problem, and What Should We Do Instead?}

In the most naive case, this procedure leads to simply 'combining the boxes'. Theories are developed by their combination or by addition of concepts, typically at the periphery of the theory, rather than by changes or redevelopment.

This process of playing Lego blocks with concepts and theories leads to overly simplistic extensions and work that is conservative rather than thought-leading or challenging. Hence, the results are theoretically sound, but applicable only to the specific area for which a theory extension was proposed. This is how the IS field ends up with dozens of extensions of TAM into various niche fields, as well as hundreds of different operationalisations of TAM for different phenomena. It is interesting to note that the majority of these are not actually published in the top-tier journals, but, due to their conservative nature, are relegated to secondtier outlets.

Instead of playing Lego blocks with theories and concepts, researchers should identify gaps in knowledge by what is left unexplained by existing theories. These 'mysteries' might not only require extension of theory, they might also lead to re-conceptualisation of an entire area and thus produce interesting and challenging new theories. These paradigm shifts have occurred in many other areas of science but are relatively rare in information systems. Examples might be to examine organisations not as systems of control and input-output, but as 'orderly arrangements of individual human interactions' (Tannenbaum, 1962, p. 236) or other metaphors (Evermann, 2005a; Reed, 1992; Walsham, 1991). System implementation projects can also be conceptualised using metaphors such as organisational drift and organisational politics, rather than the more common conceptualisation as a set of activities to be optimised (Hirschheim and Newman, 1991; Kendall and Kendall, 1993; Kling and Iacono, 1984).

\section{Reference Disciplines Lost in Translation}

\section{Description}

Information systems has a wide range of reference disciplines, and many areas of inquiry in IS can be considered as special cases of wider areas of inquiry (Baskerville and Myers, 2002). For example, the formation of attitudes and beliefs towards technology can be considered as a special case of the formation 
of attitudes and beliefs in general - the domain of social psychology. The study of IS service quality was based extensively on the study of service quality by marketing researchers.

The issues with our reporting of knowledge from reference disciplines are threefold. First, there is a danger of being 'lost in translation', where details and nuances of original theory are lost in the process of appropriation by IS authors. The second is the time lag that frequently exists from the reference discipline to publication within the IS literature. Frequently, IS researchers do not acknowledge or cite new knowledge from reference disciplines until it has been published in our own leading journals. Then, once it has been published in our own leading journals, we often stop at that point in development, and do not reference later developments within the reference discipline. Finally, we do not critically re-examine previous IS studies in the light of new insights from reference disciplines. We illustrate this issue with the example of psychometric literature, the use of Bunge's ontology in design science research and studies in cognitive dissonance.

\section{Why Is This A Problem, and What Should We Do Instead?}

Attitudes and perceptions - including therefore attitudes and perceptions towards technology - are psychological states. Psychometrics is a reference discipline used by IS researchers, which concerns itself with the operationalisation and measurement of psychological states. A widely used approach for modelling and measuring psychological states is latent variable theory (Borsboom, 2005; Borsboom et al., 2003).

Latent variable theory - the understanding of formative and reflective latent variables, how they should be modelled and what validity criteria to applyhas only been discussed recently in IS literature (Petter et al., 2007), despite being widely discussed in psychometric literature for more than 10 years (see, for example: Diamontopoulos, 2006; Diamontopoulos and Winklhofer, 2001; Edwards and Bagozzi, 2000; Jarvis et al., 2003).

This is a problem because the modelling and interpretation of formative latent indicators, and evaluations of model quality and fit, are quite different to that for reflective latent variables (Chin et al., 1988; Diamontopoulos and Winklhofer, 2001; Petter et al., 2007). Researchers who are unaware of this distinction run the risk of seriously mis-specifying their models. Jarvis et al. (2003) have shown that being unaware of the distinction can have dire consequences for the resulting estimates. Furthermore, widely cited models that were published before this knowledge became mainstream in IS might be mis-specified (Tate and Evermann, 2009a). 
Overall, theories of quantitative psychological measurement methods do not form part of the core of the IS discipline, but theories of attitudes and behaviour towards technology do; however, these theories depend heavily on methods, metrics and heuristics developed in psychometrics. It is likely that we will continue to need to look to psychometrics for guidance as to how best to conduct psychological measurement.

A second example might be the adoption of Bunge's ontology to ground much of current design science research. It should be noted that Bunge's ontology is an eight-volume work, yet Wand and Weber (1993) have limited their adoption to about half of the first volume, claiming that this is all that is required for IS researchers, and adapting and changing the ontology in the process. Moreover, other ontologies exist that might be as appropriate or more so (Milton and Kazmierczak, 2004). While some argue that the post-hoc empirical success of this ontology in explaining different phenomena around IS design justifies the adoption of and reliance on this particular adaptation of this particular subset of this particular ontology, these studies often have challenges in validity (Evermann, 2005b). For example, rarely is the underlying theory sufficiently formalised and sufficiently specific to exclude competing explanations of the phenomena. Different authors have at times challenged the use of this ontology as inadequate (Evermann, 2005b; Wyssusek, 2005), and other areas of science have developed a very different understanding of ontology than the IS field (Noy and Hafner, 1997; Uschold and Gruninger, 1996).

Despite the increasing maturity of IS as a discipline, it behoves IS researchers to be cognisant of ongoing developments in reference disciplines, rather than relying exclusively on the most recent 'IS translation' of the theory published in a leading IS journal.

A final example is cognitive dissonance theory. Based on original work by Festinger (1957), it has been considerably refined in a process of cumulative studies since then (for a summary of this development, see Cooper, 2007). Yet, even recent IS studies that are based on cognitive dissonance make reference only to Festinger's original work (Bhattacherjee and Premkumar, 2004; Pavlou and Gefen, 2005). Important limitations or re-conceptualisation in light of selfimage and self-perception theory are omitted or glossed over. For example, Festinger's (1957) theory of cognitive dissonance survived many challenges but has been transformed and re-conceptualised beyond what Festinger imagined in 1957. Such transformations might make the theory inapplicable in some of the situations that Bhattacherjee and Premkumar (2004) and Pavlou and Gefen (2005) describe.

When making use of reference disciplines, a literature review must include more than the original study. Theories are not static constructs and reference 
disciplines extend, constrain, re-conceptualise or otherwise adapt their theories over time. Thus, while researchers might begin with classic or seminal papers, a forward literature review is absolutely necessary. Tools such as the ISI Web of Science make forward literature reviews much easier than they used to be and leave researchers little excuse for not performing them.

\section{Obstacles in Theory Development}

There is a tension in theory development between accuracy, simplicity (parsimony) and generalisability, which are all highly valued qualities of theory. One effect of this is a tendency to focus on the more generalisable, but less accurate and salient aspects of attitudes and behaviours towards technology. Information systems researchers have sometimes been wary of engaging deeply with specific technologies as these are seen as transient phenomena; however, it is precisely in understanding and explaining the interface between people and technology artefacts that IS research has the potential to make a unique contribution (Benbasat and Zmud, 2003). In this section, we examine the issues surrounding the way we balance these three goals, and offer some suggestions as to how this could be improved.

\section{Valuing Parsimony Over Accuracy}

\section{Description}

Parsimony is frequently considered a characteristic of quality in a theory. There is, however, an inherent tension between theory parsimony and a nuanced and accurate description of the phenomenon of interest.

Parsimony is only one desirable aspect of theory. Accuracy, consistency and scope (generalisability) are also highly valued (Kuhn, 1983). Another important point that should be added is originality, which is a key publication criterion for top IS journals (Seddon, 2006). There are inherent tensions between accuracy, generalisability and simplicity (parsimony) (Figure 2.2).

This tension is not unique to IS, but is an ongoing issue within social science research (Blalock, 1982). The diversity of social phenomena tends to lead to issues with theory generalisability and parsimony (simplicity). The quest for parsimony is often the cause of a gap between models and the complexities of the real world. Although social scientists

strive for theories that are simultaneously parsimonious, highly general, and therefore applicable to a wide range of phenomena, yet precise 
enough to imply rejectable hypotheses, it does not appear possible...to achieve simultaneously all three of these ideal characteristics...my own position is that of the three, parsimony is the most expendable. (Blalock, 1982, p. 28)

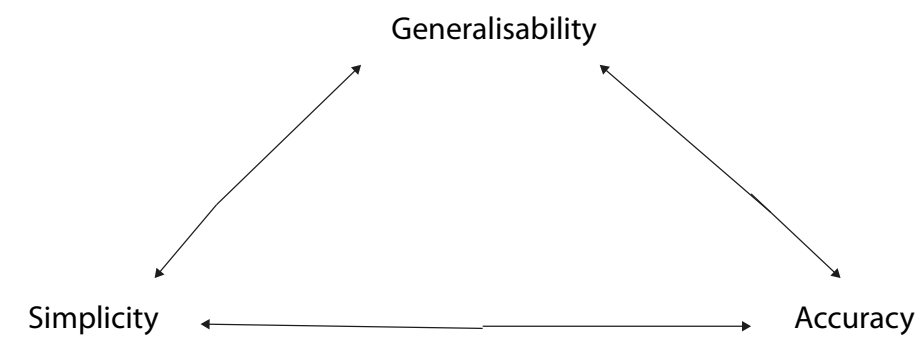

Figure 2.2 The Trade-Off Between Generalisability, Accuracy and Simplicity in Theory

\section{Why Is This A Problem, and What Should We Do Instead?}

In 1998, Robey and Marcus lamented that IS theory is not 'well positioned to recommend actions for improving the intervention' of a new technology (Robey and Markus, 1998, p. 10). Ten years later, theories of user attitudes and perceptions towards technology are still 'leading to research that is unable to provide actionable advice' (Benbasat and Barki, 2007, p. 213).

We contend that the pursuit of parsimony is at least partly to blame. To illustrate this, we compare two widely cited papers on IS success. According to Google Scholar, DeLone and McLean's (1992) IS success model has been cited more than 3000 times, including being extended and applied in multiple business contexts. It is a relatively simple model, with seven constructs, each of which, the authors suggest, could be measured (operationalised) by a set of three to five metrics. The elegance and simplicity of this model are almost certainly a major part of its appeal.

By way of contrast, we consider the critiques and alternative proposed by Ballantine et al. (1996) in their '3-D' model. Among the critiques they make of the original DeLone and McLean model are the fact that it focuses too heavily on financial aspects and does not consider human aspects, that it fails to recognise that different factors contributing to success might be carried out at different levels of the organisation and the organisational structure of the organisation might impact on IS success, that it does not take into account the iterative nature of IS systems and the degree to which learning might occur during their life cycle, the impact of the external business environment, the effectiveness of the organisation's change processes and other information systems. The resulting 3-D model attempts to incorporate these factors. 
The 3-D model is complex, with perhaps 40-50 constructs, organised in several layers, with various 'filters' and external ('exogenous') factors acting on them. It is a much more complete and accurate picture of the complexities of IS management and measurement in an organisational context than the DeLone and McLean model; however, the 3-D model would be almost impossible to operationalise and test quantitatively. It is anything but parsimonious. It is also far more likely to be useful and salient. For example, Ballantine et al.'s model would be far more useful as a guide for a post-implementation review of a recently implemented system than the more parsimonious IS success model.

That the quest for parsimony has led IS researchers to make dubious claims of explanatory success has been shown by Evermann and Tate (2009a) who, upon examining recent studies using structural equation analysis, conclude that most of the published theories do not fit the data, despite claims to the contrary by the authors. They have shown in one particular instance that the search for parsimony is to blame and that a more nuanced theory is in fact able to explain the observed data.

Overall, there is a tension between parsimonious models, which are inherently reductionist, and information systems, which as social phenomena are inherently complex. Salience for practice is likely to require a richer and more holistic understanding of the phenomena than our parsimonious models typically provide.

\section{Excessive Claims of Generalisability}

\section{Description}

There has been ongoing dialogue within the IS community about the degree to which IS researchers should aim for generalisability of theory and the tension between accuracy, simplicity and generalisability (Seddon and Lyytinen, 2008). As we discussed, there is a trade-off between generalisability, accuracy and simplicity (Figure 2.2). Within that, generalisability as well as simplicity (discussed above) is often privileged at the expense of accuracy.

One reason generalisability is valued in theory development is that it is assumed to be evidence of the development of a cumulative research tradition. Generalisable models might be created by expanding the scope (boundaries) of existing models or by combining two or more models with a more limited scope (Dubin, 1978). 


\section{Why Is This A Problem, and What Should We Do Instead?}

In their recent discussion (Seddon and Lyytinen, 2008), the panellists noted that many studies are not as representative as they claim to be, because the technologies and users that are studied vary considerably. For example, not all email or enterprise resource planning (ERP) systems are the same, and the characteristics and perceptions of individual users can vary within and between different contexts of use.

In the IS research community, issues have been raised about the state of research into user attitudes and perceptions towards technology in a special issue of the Journal of the Association of Information Systems (Benbasat and Barki, 2007; Hirschheim, 2007). Benbasat and Barki (2007) suggested that the popularity of TAM has diverted researchers away from its antecedents - in particular, the design of the IT artefact and the characteristics that make it useful. They further suggest that the addition of various constructs (other models with a different scope) such as trust and self-efficacy to TAM has created the illusion of cumulative tradition', but has not in fact extended the boundaries of the theory (Benbasat and Barki, 2007, p. 213).

As an alternative, we can both test the generalisability of some of our core constructs and improve the salience of our models for practitioners, by extending our models of attitudes and perceptions towards technology to include more consideration of the underlying technological artefact. For example, there is currently a great deal of competition in the social networking space. All leading social networking sites with large established user bases presumably meet basic expectations of usefulness, ease of use and task-technology fit, or adoption would not have been so extensive. Competition is enacted at a much more detailed level, such as (for example) the visibility, attractiveness and placement of social network software bookmarking icons. Evermann and Tate (2009b) provide an example of how the perceived presence of a social networking site bookmark can be modelled using antecedents such as visibility, which in turn has very specific antecedents such as placement and size. While it is true that this is constrained to a relatively narrow phenomenon - social networking bookmarking iconsthe value of social networking applications is currently in the billions of dollars per year, so research that leads to small gains in competitiveness is highly salient.

Overall, very small differences in technology affordances, functions and interactions might have a significant impact on competitiveness. Information systems theory should enable us to distinguish and measure those differences that are important, rather than concentrating exclusively on those aspects that are generalisable. 


\section{Failing to Distinguish Between Beliefs, Attitudes, Intentions and Behaviours}

\section{Description}

Information systems theory draws heavily on theories of attitudes and behaviour from social psychology. For example, TAM (Davis et al., 1989) and its successor, UTAUT (Venkatesh et al., 2003), both cite the theory of reasoned action (TRA) (Fishbein and Ajzen, 1975) and its successor, the theory of planned behaviour (TPB) (Ajzen, 1991), as important parts of their provenance. Although the core theories are widely known, the detailed discussion that lies behind these theories is not.

Fishbein and Ajzen (1975) distinguish between affect, cognition and conation. Affect is a person's feeling towards and evaluation of some object (person, issue or event); cognition refers to his or her knowledge, opinions, beliefs and thoughts about the object; and conation refers to his or her behavioural intentions. Fishbein and Ajzen use 'attitude' to denote affect, 'belief' to denote cognition and 'intention' to denote conation (Figure 2.3). Beliefs link an object to some attribute, which might be any trait, property, characteristic, affordance or outcome associated with that object.

Current Beliefs lead to Attitudes, Intentions and Behaviours

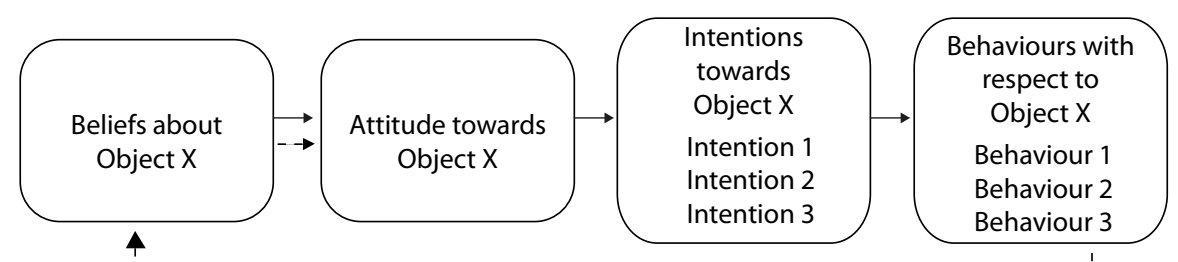

Previọius outcomes and experiences also contribute to the formation of Beliefs and 'Attitudes

\section{Figure 2.3 Beliefs, Attitudes, Intentions and Behaviours}

Fishbein and Ajzen assert that the belief concept is central to understanding attitudes, intentions and behaviours. Beliefs about an object form the basis for the formation of attitudes towards that object. Belief formation involves the establishment of a link between two aspects of an individual's world. One is direct observation via the senses of an (technological) object (for example, that a web site offers a certain information item or button to push). This gives rise to descriptive beliefs about the object. Since people rarely doubt the validity of their own senses, descriptive beliefs are usually held with maximum certainty. Beliefs that go beyond directly observable events are inferential beliefs. These are formed from descriptive beliefs - for example, the presence of certain information might be used to infer usefulness. 
Inferential beliefs might be based in the first instance on previous inferences, but Fishbein and Ajzen claim that most inferential beliefs can eventually be traced back to descriptive beliefs. The distinction between descriptive and inferential beliefs is, however, a continuum rather than a dichotomy:

At the descriptive end of the continuum, a person's beliefs are directly tied to the stimulus situation, and at the inferential end, beliefs are formed on the basis of these stimuli as well as the residues of the person's past experiences; the continuum may be seen as involving [a range from] maximal to minimal use of such past experiential residues. (Fishbein and Ajzen, 1975, p. 133)

\section{Why Is This A Problem, and What Should We Do Instead?}

Information systems theories of perceptions and attitudes towards technology have often failed to adequately distinguish between descriptive and inferential beliefs. The terms 'perception', 'user's perception' or 'customer's perception' are often used in the IS and consumer behaviour literature as catch-all terms that encompass both descriptive and inferential beliefs. For example, the perceptions of web site users of the navigability of a site are likely to be more descriptive than inferential: they are reasonably precise and likely to be well correlated to objective features such as the number of clicks required to achieve a goal. There might be some variation based on the individual, but the responses are likely to be reasonably similar between individuals, with a substantial portion of the differences in score explained by objective qualities of the site.

The belief of whether a site is easy to use, however, is a more inferential than descriptive belief. There are two issues with inferential beliefs that place them at a remove from salient features of the technology. The first is that they are much more generalised than descriptive beliefs, which greatly reduces their salience in any specific context (Tate and Evermann, 2009b). The question 'is it easy to use' is a question one could reasonably ask about a diversity of technologies, ranging from lawnmowers to surgical instruments; however, if we do not include the antecedent descriptive beliefs, which are based on the affordances of the technology then this question, although it might have the same wording, is effectively a different question when used in different contexts. The characteristics and features that contribute to respondents rating a lawnmower as 'easy to use' might include how easy it is to start, its weight and manoeuvrability, and so on, and will be different to those that contribute to the evaluation of electronic surgical instruments (for example, accuracy, visual quality and response latency). Measuring the inferential beliefs alone does not provide any clues to inform the design of either technology. 
The other issue with inferential beliefs and the subsequent formation of attitudes towards a technology is that they tend to accumulate over time and with experience (Tate and Evermann, 2009b). For example, consider two users who are asked to provide their perceptions of the trustworthiness of an e-commerce web site, and then to indicate their attitudes and intentions towards conducting e-commerce transactions on that site. One user has previously experienced credit card fraud on the Internet (but not on that site) and one has not. They will likely have similar descriptive beliefs as to whether the site offers specific features shown to be antecedent to trust in electronic commerce such as privacy and security (Pittayachawan et al., 2008); however, the user who has previously experienced credit card fraud might hold a lower degree of trust (an inferential belief) and a more negative attitude to transactions on that web site, and to e-commerce in general, because they have an experiential residue from their previous fraud experience. These unmeasured causes make the measurement of inferential beliefs and attitudes less reliable.

Overall, by understanding and explicitly modelling the differences between beliefs, attitudes, intentions and behaviours, we can create more accurate models about the formation of attitudes and intentions towards technology. In particular, we can identify beliefs about specific technology affordances as antecedent to the formation of attitudes, which has the potential to result in more accurate and salient theories.

\section{Obstacles in Research Design}

Our final set of obstacles relates to our choice of research designs to operationalise and evaluate our theories. Human attitudes and behaviours towards technologies are inherently complex social phenomena that lend themselves to multiple interpretations and explanations. We like to believe that there could be simpler sets of underlying factors that give rise to and explain some of this complexity. Hence, data reduction techniques such as factor analysis are popular, but potentially misleading. We also like to think that a carefully designed study, with a large sample and that produces results with good fit to our model, has discovered something meaningful about the world. This might be the case, but we suggest that we are in danger of moving too quickly and easily from one welldesigned and executed study to an assumption of 'fact'. We seldom replicate studies, examine alternative models or examine the possibilities arising from unexpectedly positive or negative results. 


\section{Inappropriate Use of Factor Analysis}

\section{Description}

Factor analysis is frequently used inappropriately to 'discover' psychological constructs. This description is summarised from a longer and somewhat more technical discussion in a special issue of Multivariate Behavioural Research, which was devoted to discussion of factor analysis.

Maraun (1996b) identifies two fallacies that are often associated with the use of exploratory factor analysis (EFA). The first is the assumption that the common factors of factor analysis are necessarily underlying, hidden, unmeasurable (directly) or unobservable (directly) variables. The second is the assumption that factor analysis detects the existence of these variables and their influence on the measurable variables (indicators, survey questions, survey items).

In reality, common factors identified in EFA are none of these things. This is because in EFA the proof of the 'existence' of the factor is internal to the analysis, and factors are constructed by the analysis, not hypothesised a priori. According to Maraun (1996b), claims that factor analysis deals with some other factor variate - for example, a hypothetical (existing external to the data) variate-are 'confused'.

\section{Why Is This A Problem, and What Should We Do Instead?}

When EFA claims to have 'discovered' psychological latent factors, such as attitudes towards technology, the exploratory factor analysis is doing double duty. The same set of calculations that constructs the factors in the first place cannot also be used as evidence for their independent existence in the minds of the respondents. The researcher cannot, in the same breath, build or construct something and claim to have discovered it. This is a fallacy known as factor reification.

The impact of this is that many models contain constructs 'discovered' by factor analysis to which researchers then apply names and definitions, and specify reflectively (antecedent to their indicators). Because EFA merely decomposes the matrix of undirected correlations it cannot distinguish between antecedents and consequents. Hence, many of these constructs are not in fact reflective latent variables, but composites that might contain both formative and reflective items. That is, some of these highly correlated variables might be consequents or antecedents of others. For example, 'information quality' is a component of Barnes and Vidgen's (2002) e-Qual instrument, and has items that include accuracy, timeliness and the appropriateness of the presentation format. Since it is possible for information to be accurate but not timely or appropriately presented, and so on, there cannot be a single common cause (information quality) underlying all 
these measures. There are almost certainly relationships within and between these measures that have not been investigated because of the mistaken assumption that a common-cause factor has been 'discovered'. Because they are not necessarily correlated (remember that a single counter-example suffices), the identified correlations based on which the EFA techniques constructed the common factor must be considered incidental or spurious, albeit typical. It is this typicality that needs to be investigated, as there could be a more distal common cause.

We note that the same issues do not apply to more rigorous techniques such as confirmatory factor analysis (CFA), which specifies a model a priori and evaluates the degree to which the data fit the hypothesised model. In this case, the argument for the existence of the factors is external to the analysis (in the theory used to construct the model). Here too, however, the researchers must be cautious to distinguish between proximal and distal factors: latent variables should represent proximal factors (common causes that are most immediately antecedent to the measurement observations) (Hayduk, 1996). In a CFA setting, however, the true model might not necessarily be a simple common-cause latent variable, despite such a model fitting the observed data. This could be due again to incidental but typical correlations that hint at a more distal common cause or at more complex processes underlying the data.

Overall, we suggest that exploratory factor analysis has a limited role to play in building theory of attitudes and behaviour towards technology. It might be preferable to use qualitative methods to explore the perceptions, attitudes and behaviours of users of an information technology in context. The resultant theory can then be specified in advance and evaluated using theory testing methods, such as confirmatory factor analysis and structural equation modelling.

\section{Lack of Replicatory Studies}

\section{Description}

Replication has been described as the key to generalisation (Hubbard and Armstrong, 1994) and the most important criterion of scientific knowledge (Rosenthal and Rosnow, 1984); so a discussion of replication is related to our earlier discussion of the danger of excessive claims of generalisability. Many widely cited theories in IS are based on samples of several hundred responses, across perhaps three or four organisations. On the basis of this, the authors claim results that are generalisable to comparable contexts, or some might say, over-claim (Seddon and Lyytinen, 2008).

Information systems researchers typically describe their method in considerable detail with the intention that it should be replicable; however, very few 
replicatory studies in IS are ever conducted or published. Within the social sciences, this problem is not restricted to IS; researchers in marketing (Hubbard and Armstrong, 1994), psychology (Schmidt, 2009) and economics (Arulampalam et al., 1997) have lamented the lack of replicatory studies and the difficulties in getting them published. Replication studies are often considered uninteresting, unoriginal and potentially career limiting (Hubbard and Armstrong, 1994; Schmidt, 2009).

Obviously, a direct replication of a survey conducted in a sample drawn from a population in a social context at a point in time is very difficult; however, there are a number of types of replication and reanalysis studies. These can involve keeping various combinations of the data, the model, the method, the sample, the context or the time horizon of the original study constant, while varying other characteristics (Arulampalam et al., 1997; Schmidt, 2009). Various types of replication can be used for different purposes, including controlling for error or fraud, generalising the results to a larger or different population or verifying the underlying hypothesis by using a different operationalisation (Schmidt, 2009). Given the relatively restricted samples and contexts in which many of our studies are conducted, we are particularly interested in the opportunities for replicating the models and methods from existing IS studies with new populations in different contexts, although other types of replication could also be valuable in some circumstances.

\section{Why Is This A Problem, and What Should We Do Instead?}

A review of 20 replicatory studies in marketing found that only 15 per cent of those published confirmed the original findings (Hubbard and Armstrong, 1994). There is no reason to believe the situation would be markedly different in information systems. More reanalysis and replication studies are required to address the potential issue of excessive claims of generalisability, and to ensure confidence in our core body of knowledge.

Although direct replications are difficult outside a laboratory setting, the main obstacle to conducting other types of replicatory studies in social science fields seems to be obtaining raw data from previously published studies for reanalysis or meta-analysis, and the perceived difficulty in publishing the studies (Habing, 2003; Hubbard and Armstrong, 1994; Schmidt, 2009). A variety of solutions has been proposed, many of which have potential relevance to IS researchers.

Journal editors could require that raw data and copies of the procedures used in the research be retained and made available for subsequent reanalysis or meta-analysis. This policy is endorsed by major journals in psychology and marketing (Hubbard and Armstrong, 1994) and could easily be adopted within the IS community. Further, a better understanding of replication and reanalysis, 
backed by taxonomies such as that provided for psychology research by Schmidt (2009) could be developed. Editorial guidelines for conducting and publishing replications, such as those proposed by Arulampalam et al. (1997) for labour economics could be developed. Journals could have replication sections, special issues or a replication editor (Arulampalam et al., 1997; Hubbard and Armstrong, 1994).

\section{Failure to Consider Alternative Models}

\section{Description}

Popular data analysis techniques allow the researcher to assess, holistically, an entire theory by means of latent variable models. For covariance analysis, the researcher specifies an a-priori model that is tested against the data. What is often neglected is the fact that even if the model fits the data, it might not be the only one. In a trivial example, there are covariance equivalent models that differ significantly (Hayduk, 1996), while in non-trivial cases there might be models that, while not being covariance equivalent, also exhibit good fit to the data. For partial least squares (PLS) analysis, the researcher also specifies an a-priori model, but in this case, data are only fitted to the model, with no statistical test being conducted. The objective of the fitting is to maximise the explained variance. Here, it is even more important to recognise that other models could yield as good or better objective fit functions than the one specified. This problem is not unique to survey work using latent variable models. In many experimental studies, researchers do not develop alternative hypotheses to rule out alternative theories or explanations but in fact seek only to confirm their single a-priori hypothesis. While traditionally the experimental literature has placed special emphasis on internal validity (ruling out alternative explanations), many IS studies merely pay lip-service to this issue, suggesting that by virtue of an experimental study this point becomes a non-issue. It is, however, frequently their theoretical development leading up to the hypotheses that is at fault. For many studies, the same hypotheses could plausibly follow from alternative theories or alternative chains of reasoning. Thus, while the actual experimental study does in fact rule out so-called nuisance factors, the real issue is alternative theories generating the same hypothesis, and this is typically not sufficiently addressed.

\section{Why Is This A Problem, and What Should We Do Instead?}

Given the absence of model tests in PLS and the fact that model tests in structural equation modelling (SEM) can only reject models, these techniques are more suitable to assess the relative performance of different models and theories, rather than the absolute correctness of any particular model. This suggests that 
researchers should focus their attention on developing either competing models or, for experimental research, competing hypotheses that can differentiate between different models.

\section{Problems with Popper: An inconvenient truth?}

\section{Description}

In the IS area, but not only in the IS area, many researchers would classify themselves as positivist or at least positivistically inclined but with a more nuanced ontological and epistemological commitment. Despite this, however, many of us fail to heed Popper's argument that we can but disprove theories. Most reviewers and editors will not accept 'negative results' for publication, irrespective of the rigour of the study or the statistical power of the tests.

In an applied field such as ours, 'negative results' might have limited applicability to practice and thus are not as interesting. For example, it might not be very interesting for a business to find that web sites that offer functionality $\mathrm{X}$ are no more frequently used than those that do not. We understand that practitioners look for actionable differentiating factors (although a great amount of money could probably be saved if they also looked for non-significant effects).

We believe, however, that a distinction should be drawn between negative observations and negative theories. We agree that for the phenomena themselves, it is important that significant effects be shown; however, we believe that there is a difference between examining a non-significant phenomenon and showing that a particular theory does not explain a significant phenomenon. We can accommodate Popper and still focus on 'positive results'. Related to this is the issue of theoretical development. By not publishing 'positive results' with 'negative explanation' and insisting on rigorous a-priori theoretical development, we preclude any serendipitous discovery of theory.

\section{Why Is This A Problem, and What Should We Do Instead?}

To many, our theories seem obvious and intuitive. We would like to label this the 'Duh' phenomenon. A charitable interpretation is that all our papers are so well written that, in hindsight, the theory is indeed obvious. A more critical examination suggests that without unexplained data (for example, from a 'significant effect but negative theory' study), or a purely exploratory study, researchers have nothing to go on for developing theory than their own intuition, so that theories are necessarily obvious, intuitive and thus limited. If physicists had limited themselves to theories that their own intuitions alone create, we would probably not today have quantum theory, relativity, superconductivity 
and a host of others that are counterintuitive. These theories were invented to explain previously unexplained data. In the absence of such data and mysteries, our theories will remain applied commonsense.

In this, we are not calling for exploratory studies completely removed from theory; however, the publication of a significant effect, even when the theory fails to explain it, has potential for the development of new theories. Such effects might be simple ANOVA results or more elaborate in the form of covariance matrices from survey studies. In fact, the Journal of the AIS has a policy on providing covariance matrices to just this effect, so that future work can build on the data collected and provide better explanations. We believe this practice should be more widespread. This in no way diminishes the original paper, which should be judged based on the then existing criteria of rigour, originality and relevance.

\section{Summary: Obstacles and alternatives}

This chapter offers a brief overview and an initial discussion of a number of issues in the way we review previous research, build and test theory, and develop research designs. While we do not want to contribute to an overly negative anxiety discourse, or suggest that there is not a large amount of valuable, highquality research published in the IS field, there do appear to be some common threads in the issues we have identified.

One is the unconscious way that some of our research practices are accepted and adopted without critical reflection. This affects the way we present previous literature and tends to result in rather elastic definitions and operationalisations as we attempt to accumulate studies that are in fact incommensurable. It is possible that our insistence on identifying gaps in previous knowledge (perhaps in combination with tenure-track publishing expectations) leads to 'safe' and conservative theorising, and a tendency to add another brick to the theory wall. Another possible issue is the tendency to value some characteristics of theory that are also valued in the natural sciences, such as parsimony and generalisability, without the additional support provided by replicatory studies, reanalysis and meta-analysis. Finally, sometimes knowledge from reference disciplines gets lost in translation, which can result in inappropriate application of theories or methods from important reference disciplines, time lags in applying advances from reference disciplines and a tendency not to apply this knowledge retrospectively. A number of these issues are related, and the list is undoubtedly not comprehensive. A summary is provided in Table 2.1. 
Table 2.1 Summary of Obstacles to Theory Building

\begin{tabular}{|c|c|}
\hline $\begin{array}{l}\text { The literature } \\
\text { review }\end{array}$ & Recommendations \\
\hline $\begin{array}{l}\text { The unconsciously } \\
\text { subjective literature } \\
\text { review }\end{array}$ & $\begin{array}{l}\text { Use other literature review techniques, including descriptive literature } \\
\text { reviews, vote counting and quantitative meta-analysis. } \\
\text { Clearly articulate criteria for selection and evaluation of articles. Apply } \\
\text { current research standards and heuristics to previously published articles. } \\
\text { Recommended reading: Guzzo et al. (1987); King and He (2005). }\end{array}$ \\
\hline $\begin{array}{l}\text { Issues with meaning } \\
\text { variance }\end{array}$ & $\begin{array}{l}\text { Consider a critical analysis or a presentation of the major threads of } \\
\text { discourse focusing on the margins and areas of disagreement. } \\
\text { Recommended reading: Cooper (1988); Killduff and Mehra (1997); } \\
\text { Rosenau (1992); Sylvester and Tate (2008); Sylvester et al. (2007). }\end{array}$ \\
\hline & $\begin{array}{l}\text { Examine what is left unexplained by existing theories. Entertain the } \\
\text { possibility of re-conceptualisations of established research areas. } \\
\text { Recommended reading: Depends on the nature of the theory. }\end{array}$ \\
\hline $\begin{array}{l}\text { sciplines } \\
\text { ation }\end{array}$ & $\begin{array}{l}\text { Do not rely exclusively on the most recent 'IS translation' of theories } \\
\text { from reference disciplines, but go back to original sources as required. } \\
\text { Follow current developments in important reference disciplines to avoid } \\
\text { time lag in crossing disciplinary boundaries, and to provide criteria for } \\
\text { critical evaluation of the methods used in previously published studies. } \\
\text { Continue to follow developments in the reference discipline that occur } \\
\text { after the theory has been appropriated into information systems. } \\
\text { Recommended reading: Depends on the nature of the theory. Some } \\
\text { suggestions for theory development based on psychometrics include: } \\
\text { Borsboom (2005); Borsboom et al. (2003); Chin et al. (1988); } \\
\text { Diamontopoulos (2006); Diamontopoulos and Winklhofer (2001); } \\
\text { Edwards and Bagozzi (2000); Jarvis et al. (2003); Petter et al. (2007); } \\
\text { Tate and Evermann (2009a). }\end{array}$ \\
\hline $\begin{array}{l}\text { Theory building } \\
\text { and testing }\end{array}$ & Recommendations \\
\hline $\begin{array}{l}\text { Valuing parsimony } \\
\text { over accuracy }\end{array}$ & $\begin{array}{l}\text { Create richer, more complex and more nuanced theory that more closely } \\
\text { represents the complexity of social contexts and is more likely to be } \\
\text { actionable. } \\
\text { Recommended reading: Benbasat and Barki (2007); Blalock (1982); Kuhn } \\
\text { (1983); Robey and Markus (1998). }\end{array}$ \\
\hline $\begin{array}{l}\text { Excessive claims of } \\
\text { generalisability }\end{array}$ & $\begin{array}{l}\text { Extend theory to include salient design features and affordances of } \\
\text { technologies. } \\
\text { Conduct more replicatory and reanalysis studies (see below). } \\
\text { Recommended reading: Benbasat and Barki (2007); Dubin (1978); } \\
\text { Hirschheim (2007). }\end{array}$ \\
\hline
\end{tabular}




\begin{tabular}{|c|c|}
\hline $\begin{array}{l}\text { Failure to distinguish } \\
\text { between beliefs, } \\
\text { attitudes and } \\
\text { behaviours (core } \\
\text { theory from social } \\
\text { psychology) }\end{array}$ & $\begin{array}{l}\text { Separation of beliefs about technology from the resulting attitudes } \\
\text { allows us to accurately model the process by which people form beliefs, } \\
\text { attitudes, intentions and behaviours towards technology and address } \\
\text { the call to relate our theories to the design features of IS artefacts. The } \\
\text { resulting models have the potential to be highly salient to practice and to } \\
\text { advance the core of the discipline. } \\
\text { Recommended reading: Fishbein and Ajzen (1975); Tate and Evermann } \\
\text { (2009b). }\end{array}$ \\
\hline $\begin{array}{l}\text { Research } \\
\text { design }\end{array}$ & Recommendations \\
\hline $\begin{array}{l}\text { Inappropriate use of } \\
\text { exploratory factor } \\
\text { analysis }\end{array}$ & $\begin{array}{l}\text { Use other methods (for example, qualitative methods) to 'discover' } \\
\text { psychological constructs. Hypothesise them a priori and evaluate them } \\
\text { using theory testing methods such as CFA or SEMs. } \\
\text { Recommended reading: David (1996); Hayduk (1996); McDonald (1996); } \\
\text { Maraun (1996a, 1996b, 1996c); Mulaik (1996); Rozeboom (1996); } \\
\text { Schonemann (1996a, 1996b); Steiger (1996a, 1996b); the SEMNET } \\
\text { online forum. }\end{array}$ \\
\hline $\begin{array}{l}\text { Lack of replicatory } \\
\text { studies }\end{array}$ & $\begin{array}{l}\text { Develop methodological and editorial guidelines for conducting and } \\
\text { publishing replication and reanalysis studies. } \\
\text { Recommended reading: Arulampalam et al. (1997); Hubbard and } \\
\text { Armstrong (1994); Schmidt (2009). }\end{array}$ \\
\hline $\begin{array}{l}\text { Failure to consider } \\
\text { alternative models }\end{array}$ & $\begin{array}{l}\text { Develop, test and publish competing models. } \\
\text { Recommended reading: Hayduk (1996). }\end{array}$ \\
\hline $\begin{array}{l}\text { Problems with } \\
\text { Popper }\end{array}$ & $\begin{array}{l}\text { Publish significant effects, even if the theory does not explain them. } \\
\text { Make raw data available for future work to provide alternative } \\
\text { explanations for the data collected. }\end{array}$ \\
\hline
\end{tabular}

\section{Implications}

As IS is a practice-based field, IS researchers tend to have a strong focus on conducting empirical research to explain phenomena with real-world salience. Simultaneously, there is a widely held belief that as IS is an academic discipline, our concern should be with developing generalisable theory. These two areas of focus are sometimes in conflict. A further complication is that, despite the assertions of Baskerville and Myers (2002) that IS can be a reference discipline, many of our theories are adaptations and appropriations of theory from reference disciplines. We have a tendency to extend these IS appropriations without re-engaging deeply with either the original theories or their philosophical underpinnings. This can lead to a rather formulaic approach to theory building that follows 'best practice' in our field uncritically.

The major implication of this chapter is that quality theory building requires a deep, thoughtful and critical engagement by the researcher with the philosophy 
of science, reference disciplines, methods and data analysis literature, and the assumptions made at all stages of the research process ranging from the selection and presentation of literature, the goals and scope of the theory-building process to the selection of the research design. We recognise this is a big ask, but we believe it is essential to improve the quality of our theory building.

\section{Conclusion}

Overall, despite 20 to 30 years of quantitative research in theories of attitudes and behaviours towards information technology there is relatively little agreement about core constructs, definitions and operationalisations. This is not to suggest that all is hopeless, or that there are not significant amounts of highquality research. There is, however, evidence that there is considerable room for improvement. In this chapter, we identify a number of research issues and practices that could be impeding our disciplinary progress. We also introduce a range of literature from reference disciplines offering more in-depth discussions and alternative perspectives that might stimulate further debate.

The contribution of this chapter is to stimulate debate about some common methodological assumptions and practices of IS researchers, to present contrarian views and alternatives and to showcase recent contributions from reference disciplines.

If the practices we have critiqued are adopted uncritically then we will perpetuate the situation expressed in the meme if you do something one hundred times you should not expect a different result on the hundred and first time'. Our earnest hope is that this discussion will promote debate, critical reflection and overall quality improvement for theory building in this critical aspect of IS research.

\section{References}

Ajzen, I. (1991). The theory of planned behavior. Organizational Behavior and Human Decision Processes, 50(2), 179-211.

Arulampalam, W., Hartog, J., MaCurdy, T., \& Theeuwes, J. (1997). Replication and re-analysis. Labour Economics, 4(2), 99-105.

Babakus, E., \& Boller, G. (1992). An empirical assessment of the SERVQUAL scale. Journal of Business Research, 24(3), 253-68. 
Ballantine, J., Bonner, M., Levy, M., Martin, A., Munro, I., \& Powell, P. L. (1996). The 3-D model of information systems success: the search for the dependent variable continues. Information Resources Management Journal, 9(4), 5-14.

Barki, H. (2008). Thar's gold in them thar constructs. The Database for Advances in Information Systems, 39(3), 9-20.

Barnes, S., \& Vidgen, R. (2002). An integrative approach to the assessment of e-commerce quality. Journal of Electronic Consumer Research, 3(3), 114-27.

Baskerville, R. L., \& Myers, M. D. (2002). Information systems as a reference discipline. MIS Quarterly, 26(1), 1-14.

Benbasat, I., \& Barki, H. (2007). Quo vadis, TAM? Journal of the Association for Information Systems, 8(4), 211-18.

Benbasat, I., \& Zmud, R. W. (2003). The identity crisis within the IS discipline: defining and communicating the discipline's core properties. MIS Quarterly, 27(2), 183-94.

Bhattacherjee, A., \& Premkumar, G. (2004). Understanding changes in belief and attitude toward information technology usage: a theoretical model and longitudinal test. MIS Quarterly, 28(2), 229-54.

Blalock, H. (1982). Conceptualisation and Measurement in the Social Sciences. Beverley Hills, Calif.: Sage.

Borsboom, D. (2005). Measuring the Mind: Conceptual issues in contemporary psychometrics. Cambridge, UK: Cambridge University Press.

Borsboom, D., Mellenbergh, G. J., \& van Heerden, J. (2003). The theoretical status of latent variables. Psychological Review, 110(2), 203-19.

Carman, J. (1990). Consumer perceptions of service quality: an assessment of the SERVQUAL dimensions. Journal of Retailing, 66(1), 33-55.

Chin, J., Diehl, V., \& Norman, K. (1988). Development of an instrument measuring user satisfaction of the human-computer interface. Proceedings of the SIGCHI Conference on Human Factors in Computing Systems, Washington, DC, 213-18.

Cooper, H. M. (1988). Organising knowledge syntheses: a taxonomy of literature reviews. Knowledge, Technology and Policy, 1(1), 104-26.

Cooper, J. (2007). Cognitive Dissonance: 50 years of a classic theory. London, UK: Sage Publications. 
Curd, M., \& Cover, J. A. (1998). Philosophy of Science: The central issues. New York, NY: W. W. Norton \& Company.

David, B. (1996). Comment on: metaphor taken as math: inderterminancy in the factor model. Multivariate Behavioral Research, 31(4), 551-4.

Davis, F., Bagozzi, R., \& Warshaw, P. (1989). User acceptance of computer technology: a comparison of two theoretical models. Management Science, 35(8), 982-1003.

DeLone, W. H., \& McLean, E. R. (1992). Information systems success: the quest for the dependent variable. Information Systems Research, 3(1), 60-95.

Diamontopoulos, A. (2006). The error term in formative measurement models: interpretation and modelling implications. Journal of Modelling in Management, 1(1), 7-17.

Diamontopoulos, A., \& Winklhofer, H. (2001). Index construction with formative indicators: an alternative to scale development. Journal of Marketing Research, 38(2), 269-77.

Dubin, R. (1978). Theory Building. New York, NY: Free Press.

Edwards, J. R., \& Bagozzi, R. P. (2000). On the nature and direction of relationships between constructs and measures. Psychological Methods, 5(2), 155-74.

Evermann, J. (2005a). Organizational paradigms and organizational modelling. Proceedings of the Workshop on Business and IT Alignment (BUSITAL), Porto, Portugal, 230-9.

Evermann, J. (2005b). Towards a cognitive foundation for knowledge representation. Information Systems Journal, 15(2), 147-78.

Evermann, J., \& Tate, M. (2009a). Building theory from quantitative studies, or, how to fit SEM models. Proceedings of the $30^{\text {th }}$ International Conference on Information Systems, Phoenix, Ariz.

Evermann, J., \& Tate, M. (2009b). Constructs in the mist: the lost world of the IT artifact. Proceedings of the $30^{\text {th }}$ International Conference on Information Systems, Phoenix, Ariz.

Festinger, L. (1957). A Theory of Cognitive Dissonance. Stanford, Calif.: Stanford University Press.

Fishbein, M., \& Ajzen, I. (1975). Belief, Attitude, Intention and Behaviour: An introduction to theory and research. Reading, Mass.: Addison-Wesley. 
Goodhue, D. L., \& Thompson, R. L. (1995). Task-technology fit and individual performance. MIS Quarterly, 19(2), 213-36.

Guzzo, R. A., Jackson, S. E., \& Katzell, R. A. (1987). Meta-analysis analysis. Research in Organisational Behavior, 9, 407-22.

Habing, B. (2003). Exploratory factor analysis. Working Paper. University of South Carolina, Columbia, SC.

Hayduk, L. (1996). LISREL: Issues, debates and strategies. Baltimore, Md: The Johns Hopkins Press Ltd.

Hirschheim, R. (2007). Introduction to the special issue on 'Quo Vadis TAM: Issues and reflections on technology acceptance research'. Journal of the Association for Information Systems, 8(7), 203-5.

Hirschheim, R., \& Newman, M. (1991). Symbolism and information systems development: myth, metaphor, and magic. Information Systems Research, 2(1), 29-62.

Hubbard, R., \& Armstrong, J. S. (1994). Replications and extensions in marketing: rarely published but quite contrary. International Journal of Research in Marketing, 11(4), 233-48.

Jarvis, C. B., MacKenzie, S., \& Podsakoff, P. M. (2003). A critical review of construct indicators and measurement model misspecification in marketing and consumer research. Journal of Consumer Research, 30(2), 199-218.

Keen, P. (1980). MIS research: reference disciplines and a cumulative tradition. Proceedings of the $1^{\text {st }}$ International Conference on Information Systems, Philadelphia, Pa.

Kendall, J., \& Kendall, K. (1993). Metaphors and methodologies: living beyond the systems machine. MIS Quarterly, 17(2), 149-71.

Killduff, M., \& Mehra, A. (1997). Postmodernism and organisational research. The Academy of Management Review, 22(2), 453-81.

King, W. R., \& He, J. (2005). Understanding the role and methods of metaanalysis in IS research. Communications of the Association for Information Systems, 16(1), 665-86.

Kling, R., \& Iacono, S. (1984). The control of information systems developments after implementation. Communications of the ACM, 27(12), 1218-26.

Kuhn, T. S. (1983). Rationality and theory choice. Journal of Philosophy, 80(10), 563-70. 
Lyytinen, K., \& King, J. L. (2004). Nothing at the centre? Academic legitimacy in the information systems field. Journal of the Association for Information Systems, 5(6), 220-64.

McDonald, R. (1996). Consensus emerges: a matter of interpretation. Multivariate Behavioral Research, 31(4), 663-72.

Maraun, M. (1996a). Meaning and mythology in the factor analysis model. Multivariate Behavioral Research, 31(4), 603-16.

Maraun, M. (1996b). Metaphor taken as math: indeterminacy in the factor analysis model. Multivariate Behavioral Research, 31(4), 517-38.

Maraun, M. (1996c). The claims of factor analysis. Multivariate Behavioral Research, 31(4), 673-89.

Milton, S., \& Kazmierczak, E. (2004). An ontology of data modelling languages: a study using a common-sense realistic ontology. Journal of Database Management, 15(2), 19-38.

Mulaik, S. (1996). On Maraun's deconstructing of factor indeterminancy with constructed factors. Multivariate Behavioral Research, 31(4), 579-92.

Noy, N., \& Hafner, C. (1997). The state of the art in ontology design: a survey and comparative review. AI Magazine, 18(3), 53-74.

Parasuraman, A., Zeithaml, V., \& Berry, L. (1988). SERVQUAL: a multi-item scale for measuring consumer perceptions of service quality. Journal of Retailing, $64(1), 12-40$.

Parasuraman, A., Zeithaml, V., \& Berry, L. (1991). Refinement and reassessment of the SERVQUAL scale. Journal of Retailing, 67(4), 420-51.

Pavlou, P. A., \& Gefen, D. (2005). Psychological construct violations in online marketplaces: antecedents, consequences and moderating role. Information Systems Research, 16(4), 372-99.

Petter, S., DeLone, W., \& McLean, E. (2008). Measuring information systems success: models, dimensions, measures and interrelationships. European Journal of Information Systems, 17(3), 236-63.

Petter, S., Straub, D., \& Rai, A. (2007). Specifying formative constructs in information systems research. MIS Quarterly, 31(4), 623-56.

Pitt, L., Watson, R., \& Kavan, B. (1995). Service quality: a measure of information systems effectiveness. MIS Quarterly, 19(2), 173-87. 
Pittayachawan, S., Singh, M., \& Corbitt, B. (2008). A multitheoretical approach for solving trust problems in $\mathrm{B} 2 \mathrm{C}$ e-commerce. International Journal of Networking and Virtual Organisations, 5(3-4), 369-95.

Reed, M. (1992). The Sociology of Organisations: Themes, perspectives, and prospects. Herfortdshire, UK: Harvester Wheatsheaf.

Robey, R., \& Markus, M. L. (1998). Beyond rigor and relevance: producing consumable research about information systems. Information Resources Management Journal, 11(1), 7-15.

Rosenau, P. M. (1992). Postmodernism and the Social Sciences: Insights, inroads, and intrusions. Princeton, NJ: Princeton University Press.

Rosenthal, R., \& Rosnow, R. L. (1984). Essentials of Behavioral Research: Methods and data analysis. New York, NY: McGraw-Hill.

Rozeboom, W. (1996). What might common factors be? Multivariate Behavioral Research, 31(4), 555-70.

Schmidt, S. (2009). Shall we really do it again? The powerful concept of replication is neglected in the social sciences. Review of General Psychology, 13(2), 90-100.

Schonemann, P. H. (1996a). Syllogisms of factor indeterminacy. Multivariate Behavioral Research, 31(4), 651-4.

Schonemann, P. H. (1996b). The psychopathology of factor indeterminancy. Multivariate Behavioral Research, 31(4), 571-7.

Seddon, P. (2006). MISQ new author's workshop. Paper presented at the $11^{\text {th }}$ Pacific-Asia Conference on Information Systems (PACIS), Auckland, New Zealand, July.

Seddon, P., \& Lyytinen, K. (2008). Panel on generalisability in information systems theory. Paper presented at the $19^{\text {th }}$ Australasian Conference on Information Systems (ACIS), Christchurch, New Zealand, December.

Steiger, J. H. (1996a). Coming full circle in the history of factor indeterminacy. Multivariate Behavioral Research, 31(4), 617-30.

Steiger, J. H. (1996b). Dispelling some myths about factor indeterminacy. Multivariate Behavioral Research, 31(4), 539-50.

Sum, C.-C., Lee, Y.-S., Hays, J., \& Hill, A. (2002). Modeling the effects of a service guarantee on perceived service quality using alternating conditional expectations (ACE). Decision Sciences, 33(3), 347-83. 
Sureshchandar, G. S., Rajendran, C., \& Anantharaman, R. N. (2002). Determinants of customer-perceived service quality: a confirmatory factor analysis approach. Journal of Services Marketing, 16(1), 9-34.

Sylvester, A., \& Tate, M. (2008). Beyond the 'mythical centre': an affirmative post-modern view of SERVQUAL research in information systems. Paper presented at the $16^{\text {th }}$ European Conference on Information Systems (ECIS), Galway, Ireland, June.

Sylvester, A., Tate, M., \& Johnstone, D. (2007). Re-presenting the literature review: a rich picture of service quality research in information systems. Paper presented at the $11^{\text {th }}$ Pacific Asia Conference on Information Systems (PACIS), Auckland, New Zealand, July.

Tannenbaum, A. S. (1962). Control in organizations: individual adjustment and organizational performance. Administrative Science Quarterly, 7(2), 236-57.

Tate, M., \& Evermann, J. (2009a). Descendents of ServQual in online services research: the end of the line? Paper presented at the $15^{\text {th }}$ Americas Conference on Information Systems (AMCIS), San Francisco, Calif., August.

Tate, M., \& Evermann, J. (2009b). Perceptive users with attitudes: some heuristics of theorizing. Proceedings of the International Conference on Information Systems (ICIS 2009), Phoenix, Ariz.

Teo, T., Srivastava, S., \& Jiang, L. (2009). Trust and electronic government success: an empirical study. Journal of Management Information Systems, 25(3), 99-131.

Uschold, M., \& Gruninger, M. (1996). Ontologies: principles, methods, and applications. Knowledge Engineering Review, 11(2), 93-136.

Venkatesh, V., Morris, M., Davis, G. B., \& Davis, F. D. (2003). User acceptance of information technology: towards a unified view. MIS Quarterly, 27(3), 425-78.

vom Brocke, J., Simons, A., Niehaves, B., Riemer, K., Plattfaut, R., \& Cleven, A. (2009). Reconstructing the giant: on the importance of rigour in documenting the literature search process. Paper presented at the $17^{\text {th }}$ European Conference on Information Systems (ECIS), Verona, Italy, June.

Walsham, G. (1991). Organizational metaphors and information systems research. European Journal of Information Systems, 1(12), 83-93.

Wand, Y., \& Weber, R. (1993). On the ontological expressiveness of information systems analysis and design grammars. Journal of Information Systems, 3(4), $217-37$. 
Weber, R. (1997). Ontological Foundations of Information Systems. Melbourne, Vic.: Coopers \& Lybrand.

Webster, J., \& Watson, R. T. (2002). Analyzing the past to prepare for the future: writing a literature review. MIS Quarterly, 26(2), xiii-xxiii.

Wyssusek, B. (2005). On the foundation of the ontological foundation of conceptual modeling grammars: the construction of the Bunge-WandWeber ontology. Proceedings of the $1^{\text {st }}$ International Workshop on Philosophical Foundations of Information Systems Engineering (PHISE'05), Porto, Portugal.

Yang, Z., Cai, S., Zhou, Z., \& Zhou, N. (2005). Development and validation of an instrument to measure user-perceived service quality of information presenting web portals. Information and Management, 42(4), 575-89. 